\title{
TIME-DEPENDENT BEHAVIOUR OF A CLASS F FLY ASH-BASED GEOPOLYMER CONCRETE
}

\author{
Arnaud Castel ${ }^{1}$, Steve Foster ${ }^{2}$, James Aldred ${ }^{3}$ \\ ${ }^{1}$ A/Professor, Centre for Infrastructure Engineering and Safety, School of Civil and Environmental Engineering, The \\ University of New South Wales, Sydney, Australia \\ ${ }^{2}$ Professor, Centre for Infrastructure Engineering and Safety, School of Civil and Environmental Engineering, The \\ University of New South Wales, Sydney, Australia \\ ${ }^{3}$ AECOM, Advanced Materials and Strategic Asset Management, Sydney, Australia
}

\begin{abstract}
The main purpose of this research is to study the time dependent behaviour of a geopolymer concrete. The geopolymer binder is composed of $85.2 \%$ of low calcium fly ash and only $14.8 \%$ of GGBFS (Ground Granulated Blast Furnace Slag). Both drying shrinkage and creep are studied. Tests were performed on small size specimens according to Australian Standard AS1012.13 for shrinkage and AS1012.16 for creep. Different curing regimes at elevated temperature were used. All experimental results were compared to Australian Standard AS3600 predictions. Curing regime plays an important role on both creep and drying shrinkage of class $F$ fly ash based geopolymer concrete. A minimum of three days at $40^{\circ} \mathrm{C}$ or one day at $80^{\circ} \mathrm{C}$ is required to obtain final drying shrinkage strains similar or less than the one predicted by AS3600 for OPC concrete. Creep strains are reduced of about $70 \%$ compared to predicted OPC concrete values when the geopolymer concrete was cured for three days at $40^{\circ} \mathrm{C}$. After 7 days at $80^{\circ} \mathrm{C}$, creep strains were very low.
\end{abstract}

Keywords: sustainability, geopolymer concrete, fly ash, slag, creep, shrinkage

\section{INTRODUCTION}

Over the last two decades, geopolymer concretes have emerged as novel engineering materials with the potential to become a substantial element in an environmentally sustainable construction and building products industry. Geopolymer concretes exhibit many of the characteristics of traditional concretes, despite their vastly different chemical constituents and reactions. The mixing process, the workability of freshly mixed geopolymers, the mechanical characteristics of the hardened material appears to be similar to those for traditional OPC concretes. However, only a few attempts to assess the drying shrinkage and creep characteristics of fly ash based geopolymer concrete are available in the literature. A study by Wallah and Rangan [1, 2] at Curtain University of Technology in Australia, showed that heat-cured fly ash-based geopolymer concrete undergoes low creep, about $50 \%$ of the creep usually observed for OPC based concrete as predicted by the Australian Standard AS3600-2009. Tests specimens were cured at $60^{\circ} \mathrm{C}$ for 24 hours. The creep tests were started on the 7 th day after casting and the sustained load applied was 40 per cent of the compressive strength as determined on the day when the creep testing started. Drying shrinkage was also studied using two curing procedures: (i) ambient temperature for 3 days; and (ii) heat cured at $60^{\circ} \mathrm{C}$ for $24 \mathrm{hrs}$ and then 2 days in water at $23^{\circ} \mathrm{C}$. All shrinkage tests were started after 3 days. The drying shrinkage strain of ambientcured specimens was in the order of 1500 micro-strains after three months, which is about two to three times higher than that expected for an equivalent OPC based concrete. Heat cured specimens however performed very well, with only
100 micro-strains after three months. More recently, SagoeCrentsil [3] carried out similar tests using a similar low calcium fly ash geopolymer concrete. Tests specimens were cured at $60^{\circ} \mathrm{C}$ for 6 hours only and then stored in a fog room at $23^{\circ} \mathrm{C}$. Creep and shrinkage tests were started after 28 days and 7 days respectively. Creep results were similar to those obtained by Wallah [2]. The strain due to drying shrinkage of ambient-cured specimens was in the order of 250 microstrains after three months, which is higher than the ones obtained by Wallah [1]. This is likely because of the shorter heat curing duration but, according to AS3600-2009 [4], it is still about half the value predicted for an equivalent OPC based concrete.

In this paper, further investigations are carried out in order to assess the influence of the age of the geopolymer concrete when the shrinkage test starts. Shrinkage tests were started 24 hours, 3 days or 8 days after casting. It is important to assess the drying shrinkage as early as possible because it is responsible for early age cracking that occurs when the concrete does not have much strength. According to ASTM C157 [5] shrinkage tests must start 24 hours after casting. Moreover, alternative curing temperatures $\left(40^{\circ} \mathrm{C}\right.$ and $\left.80^{\circ} \mathrm{C}\right)$ and duration are explored. Creep tests were started after 8 days considering two alternative heat curing regimes: $40^{\circ} \mathrm{C}$ and $80^{\circ} \mathrm{C}$. This work will contribute to increasing the amount of experimental data available in the literature regarding the time-dependent behaviour of low calcium fly ash geopolymer concrete. 


\section{EXPERIMENTAL PROGRAM}

\subsection{Geopolymer Binder}

A preliminary testing programme [6] was undertaken using fly ash (FA) from Eraring Power Station in New South Wales, Australia, Kaolite high-performance ash (HPA) from Callide Power Station in Queensland, Australia, and ground granulated blast-furnace slag (GGBFS). The chemical compositions of the FA, HPA and GGBFS are presented in Table 1 . Both fly ashes are low calcium class F fly ash. The grading curves for the FA, HPA and GGBFS are shown in Figure 1. The aim of the experimental programme was to investigate the effect of blending different types of aluminosilicate materials. Fifteen series of geopolymer mortar with different mix proportion were tested after 28 days [6]. The alkaline solution was made from a mixture of 12 molar (M) sodium hydroxide $(\mathrm{NaOH})$ solution and sodium silicate solution with $\mathrm{Na}_{2} \mathrm{O}=14.7 \%, \mathrm{SiO}_{2}=29.4 \%$ and $\mathrm{H}_{2} \mathrm{O}=55.9 \%$ by mass. A constant mass ratio of sodium silicate solution to sodium hydroxide solution of 2.5 was used and the mass ratio of alkaline solution to aluminosilicate material was $0.55 .24 \mathrm{~h}$ after casting, the specimens were demoulded and cured in a $90^{\circ} \mathrm{C}$ water bath for a further 7 days. Using this hot curing process, the optimum blend leading to the highest compressive strength was $67.2 \%$ FA, $18 \%$ of HPA and $14.8 \%$ of GGBFS. Thus, about $85.2 \%$ of the blend is composed of low calcium class F fly ash. The same aluminosilicate blend and activator are used in this study.

\subsection{Aggregate}

Sydney sand was used as fine aggregate. Coarse Aggregate was $10 \mathrm{~mm}$ nominal size crushed basalt. The grading curves of both types of aggregate are presented in Figure 2.

\subsection{Geopolymer Concrete Mix Design and Batching}

\section{Procedure}

The Geopolymer concrete mix is presented in Table 2. The triple aluminosilicate blend was mixed dry for about $3 \mathrm{~min}$ together with all aggregates prior to gradually add the alkaline solution and then the free water. The geopolymer concrete was compacted by using a poker vibration just after being poured in the moulds in two phases. The workability of the fresh concrete was assessed using the standard slump test. The slump obtained was $130 \mathrm{~mm}$.

Table 1: Fly ash and GGBFS chemical compositions

\begin{tabular}{|c|c|c|c|}
\hline Element & FA & HPA & GGBFS \\
\hline $\mathrm{SiO}_{2}$ & 66.56 & 45.14 & 31.52 \\
\hline $\mathrm{Al}_{2} \mathrm{O}_{3}$ & 22.47 & 33.32 & 12.22 \\
\hline $\mathrm{FeO}_{3}$ & 3.54 & 11.99 & 1.14 \\
\hline $\mathrm{CaO}$ & 1.64 & 4.13 & 44.53 \\
\hline $\mathrm{K}_{2} \mathrm{O}$ & 1.75 & 0.13 & 0.33 \\
\hline $\mathrm{Na}_{2} \mathrm{O}$ & 0.58 & 0.07 & 0.21 \\
\hline $\mathrm{MgO}$ & 0.65 & 1.37 & 4.62 \\
\hline $\mathrm{MnO}$ & 0.06 & 0.23 & 0.36 \\
\hline $\mathrm{P}_{2} \mathrm{O}_{5}$ & 0.11 & 0.56 & 0.02 \\
\hline $\mathrm{TiO}_{2}$ & 0.88 & 2.19 & 1.03 \\
\hline $\mathrm{SO}_{3}$ & 0.1 & 0.48 & 3.24 \\
\hline $\mathrm{LOI}^{*}$ & 1.66 & 0.41 & 0.79 \\
\hline
\end{tabular}

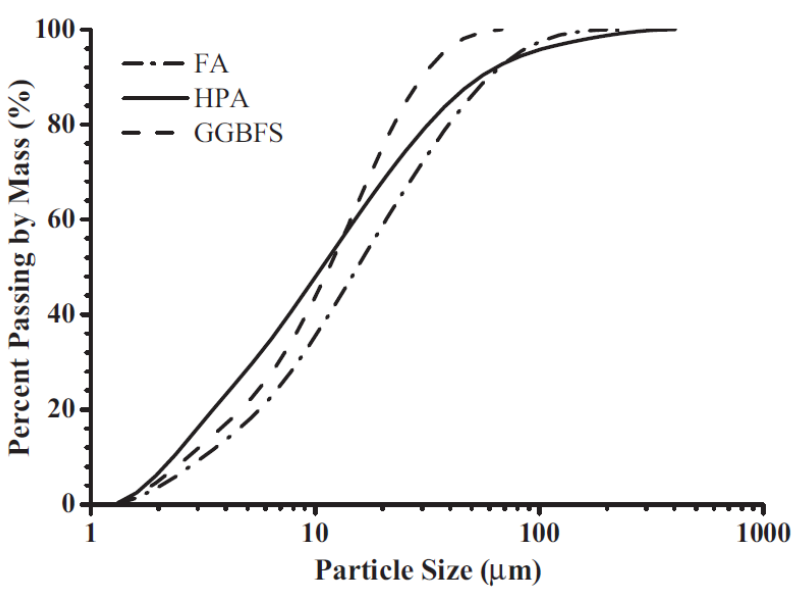

Fig 1: Grading curves for the FA, HPA and GGBFS

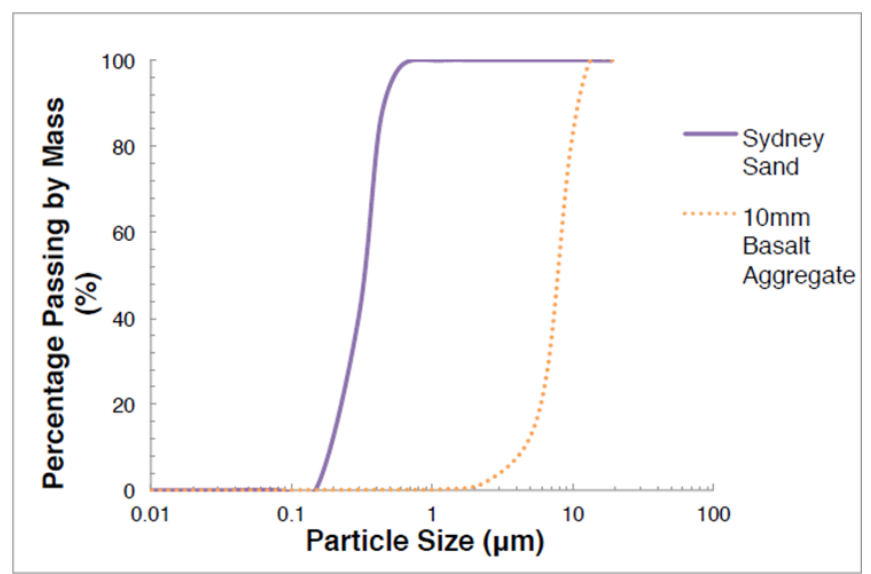

Fig 2: Grading curves of fine and coarse aggregates

\subsection{Curing Procedures}

Three curing procedures were adopted for specimens used for the drying shrinkage tests:

1D40-Curing: After casting, specimens were sealed to prevent excessive loss of moisture, stored in $40^{\circ} \mathrm{C}$ oven for 1 day. Shrinkage tests were started after 24hrs.

- $\quad$ 1D80-Curing: After casting, specimens were sealed to prevent excessive loss of moisture, stored in $80^{\circ} \mathrm{C}$ oven for 1 day. Shrinkage tests were started after $24 \mathrm{hrs}$.

- 3D40-Curing: After casting, specimens were sealed to prevent excessive loss of moisture, stored in $40^{\circ} \mathrm{C}$ oven for 3 days. Shrinkage tests were started after 3 days.

The two curing procedures used for creep test specimens are:

3D40-Curing: After casting, specimens were sealed to prevent excessive loss of moisture, stored in $40^{\circ} \mathrm{C}$ oven for 3 days and then stored in a controlled room with $23^{\circ} \mathrm{C}$ temperature and $50 \%$ relative humidity. Creep tests were started after 8 days.

8D80-Curing: After casting, specimens were sealed to prevent excessive loss of moisture, stored in $40^{\circ} \mathrm{C}$ oven for 1 day and then cured in a $80^{\circ} \mathrm{C}$ water bath 
for a further 7 days. Creep tests were started after 8 days.

Table 2: Geopolymer concrete mix

\begin{tabular}{lc}
\hline \multicolumn{1}{c}{ Materials } & $\begin{array}{c}\text { Percentage by Mass } \\
(\%)\end{array}$ \\
\hline Coarse Aggregate & 48.5 \\
Fine Aggregate & 30.1 \\
StandardFly Ash (FA) & 8.2 \\
Activator Solution & 6.7 \\
Free Water & 2.4 \\
High Performance Fly Ash (HPA) & 2.2 \\
Ground GranulatedBlastFurnace Slag & 1.8 \\
\hline
\end{tabular}

\subsection{Testing Program}

The compressive strength and the instantaneous elastic modulus were measured after 28 days on concrete cylinders $($ diameter $=100 \mathrm{~mm}$, height $=$ $200 \mathrm{~mm}$ ).

- The drying shrinkage tests were performed on $75 \times 75 \times 300 \mathrm{~mm}$ prisms in accordance with AS1012.13 [7]. During the tests the specimens were kept in a controlled temperature environment. The temperature and the relative humidity were maintained at about $23^{\circ} \mathrm{C}$ and $50 \%$ respectively. Drying shrinkage tests were started after $24 \mathrm{hrs}$ for curing conditions 1D40-Curing and 1D80-Curing, after 3 days for curing condition 3D40-Curing and after 8 days for curing condition 8D80-Curing. Three specimens were tested for each curing condition for about 60 days.

The creep tests were performed on $100 \mathrm{~mm}$ diameter cylinders with $200 \mathrm{~mm}$ height in accordance with Australian Standard AS1012.16 [8] (methods of testing concrete - determination of creep of concrete cylinders in compression). All creep tests were started 8 days after casting and the sustained load applied was $40 \%$ of the compressive strength as determined on the day of initiating creep testing. Three specimens were tested for each curing condition for about 60 days.

Both shrinkage and creep results are compared to the values calculated for an equivalent OPC based concrete using Australian Standards AS3600 [4].

\section{EXPERIMENTAL RESULTS}

\subsection{Mechanical Characteristics}

Figures 3 and 4 show the increase of the average compressive strength and elastic modulus respectively versus the duration of the heat curing period at $80^{\circ} \mathrm{C}$. All measures were performed 28 days after casting. For compressive strength, three tests were performed for each curing condition. The elastic modulus was measured using one specimen only. Figure 3 shows that the compressive strength of the geopolymer concrete increases greatly with the increasing duration of the $80^{\circ} \mathrm{C}$ curing period. The maximum average compressive strength measured was about $58 \mathrm{MPa}$ and was obtained after 7 days of heat curing. $80^{\circ} \mathrm{C}$ curing for one day only led to an average compressive strength of about $36 \mathrm{MPa}$. On the contrary, the benefit in increasing the duration of the $40^{\circ} \mathrm{C}$ curing period on the compressive strength is only moderate. Variations within the compressive and tensile strengths are reasonably low for all conditionss. Figure 4 shows that the elastic modulus is very close to the maximum possible value after one day only in the $80^{\circ} \mathrm{C}$ water. The benefit in increasing the duration of the $40^{\circ} \mathrm{C}$ curing period on the elastic modulus is limited.

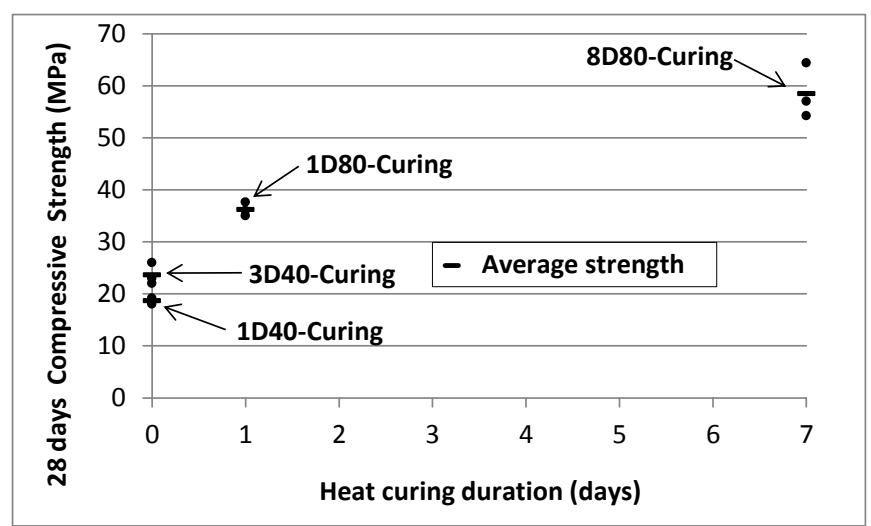

Fig 3: Increase in 28 days compressive strength versus the duration of the heat curing period.

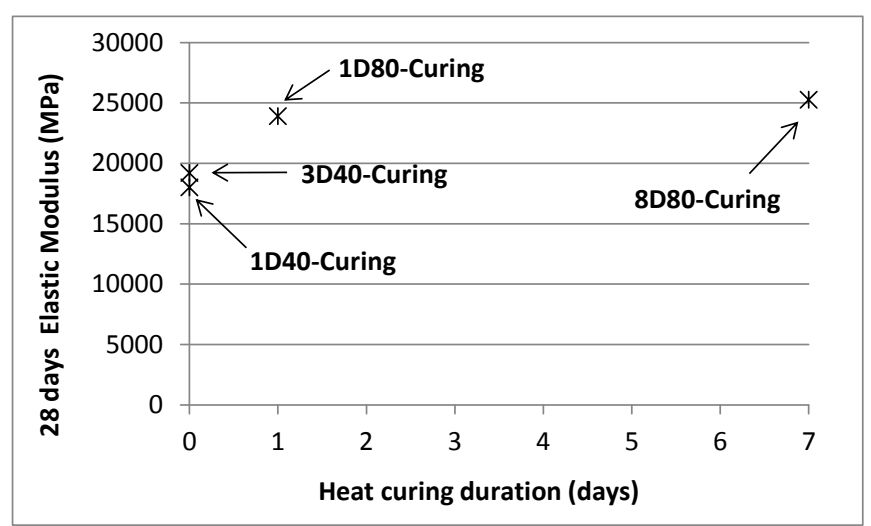

Fig 4: Increase in 28 days elastic modulus versus the duration of the heat curing period.

\subsection{Drying Shrinkage Tests}

Figure 5 shows the drying shrinkage measured on the specimens cured one day at $40^{\circ} \mathrm{C}$ and $80^{\circ} \mathrm{C}$. In Figure 5 , experimental results are compared to the values calculated for an equivalent OPC based concrete using Australian Standards AS3600 [4]. $40^{\circ} \mathrm{C}$ curing for one day leads to about 3 times the drying shrinkage strain calculated using Australian Standards AS3600. On the contrary, $80^{\circ} \mathrm{C}$ curing for one day reduces drastically the drying shrinkage strain in order to meet Australian Standards AS3600 requirement. Alternatively, a minimum of three days curing at $40^{\circ} \mathrm{C}$ is required in order to meet Australian Standards AS3600 requirement (Figure 6). But, if drying shrinkage is similar after one day at $80^{\circ} \mathrm{C}$ or three days at $40^{\circ} \mathrm{C}$, the mechanical 
characteristics of the geopolymer concrete at 28 days are still very different (Figures 3 and 4). It is important to note that the repeatability of results over three tests is very good for all curing procedures.

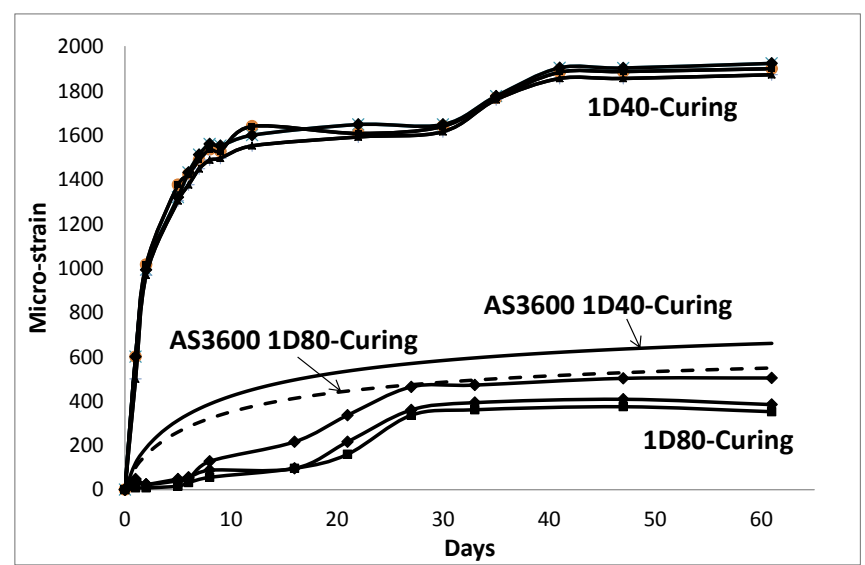

Fig 5: Drying shrinkage measured on the specimens cured one day at $40^{\circ} \mathrm{C}$ and $80^{\circ} \mathrm{C}$ (Shrinkage tests were started after 24 hours)

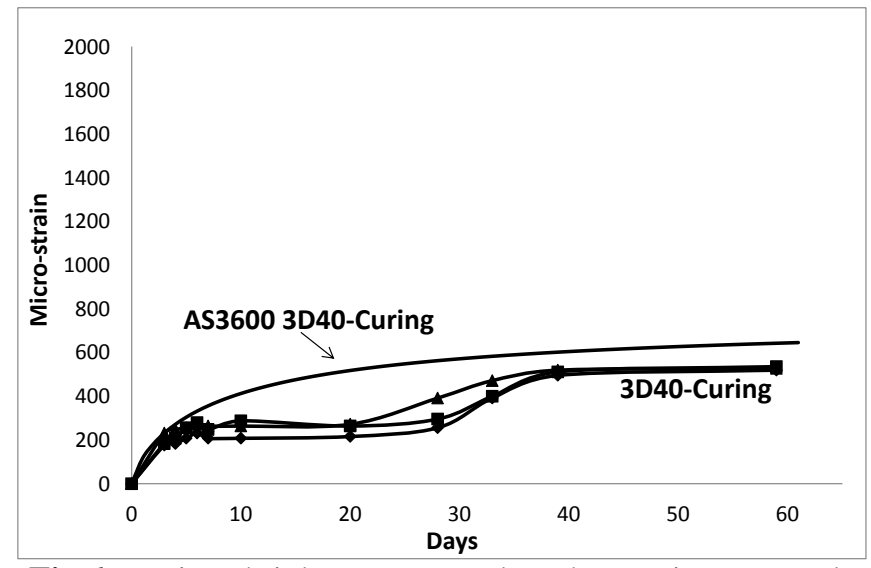

Fig 6: Drying shrinkage measured on the specimens cured three days at $40^{\circ} \mathrm{C}$ (Shrinkage tests were started after 3 days)

\subsection{Creep Tests}

Figures 7 and 8 show the creep coefficient (Equation 1) obtained for curing conditions 3D40-Curing and 8D80Curing respectively and values calculated for an equivalent OPC based concrete using Australian Standards AS3600 (AS3600, 2009).

$$
\varphi_{\mathrm{cc}}(\mathrm{t})=\frac{\varepsilon_{\mathrm{cc}}(\mathrm{t})}{\varepsilon_{\mathrm{e}}}
$$

where $\square_{\text {cc }}(t)$ is the creep coefficient, $t$ is the time (in day), $\square_{c c}(t)$ is the time dependant concrete strain due to creep and $\square_{\mathrm{e}}$ is the instantaneous elastic strain when applying the sustained loading. The creep coefficient is about the third of the one calculated using Australian Standards AS3600 for the specimens cured three days at $40^{\circ} \mathrm{C}$, which is in total accordance with results of the literature [1-3]. After 7 days at $80^{\circ} \mathrm{C}$, the creep coefficient is reduced down to about 0.2 in average. As in the case of the shrinkage tests, the repeatability of results over three tests is very good for all curing procedures.

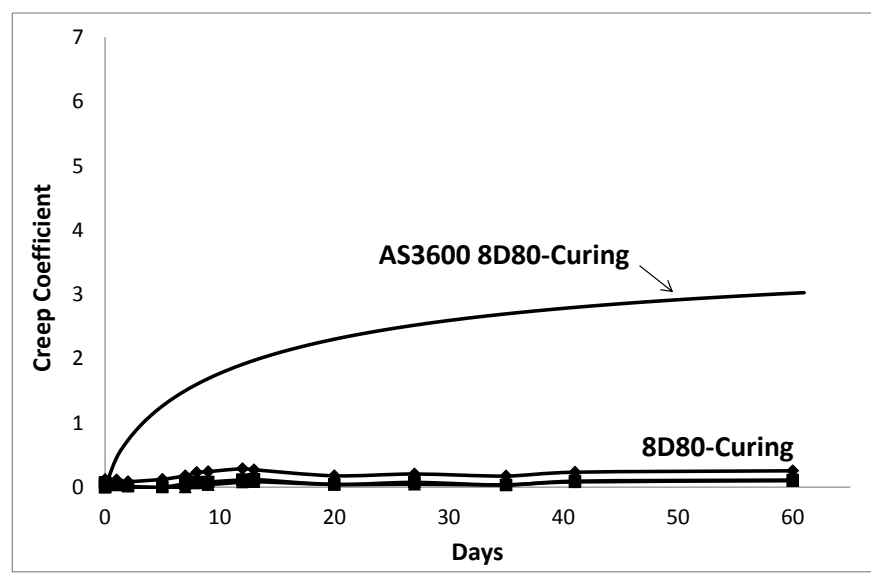

Fig 7: Creep coefficient obtained for curing condition 3D40-Curing

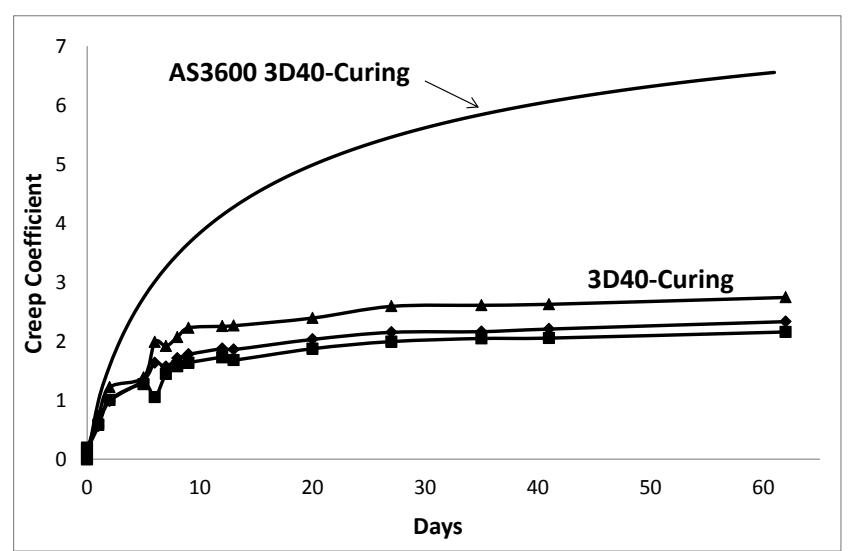

Fig 8: Creep coefficient obtained for curing condition 8D80-Curing

\section{CONCLUSION}

Curing at low temperature such as $40^{\circ} \mathrm{C}$ requires a minimum of three days in order to meet Australian Standards AS3600 requirement. When the shrinkage tests were started after one day only, shrinkage strains were about three times the ones calculated using Australian Standards AS3600. One day of cure at $80^{\circ} \mathrm{C}$ at is enough in order to meet Australian Standards AS3600 requirement even if starting the tests one day after casting.

As already reported in the literature, heat-cured fly ashbased geopolymer concrete undergoes low creep. The creep coefficient was about the third of the one calculated using Australian Standards AS3600 for the specimens cured three days at $40^{\circ} \mathrm{C}$. After 7 days at $80^{\circ} \mathrm{C}$, creep strains tend to values close to zero.

It is important to note that the consistancy of results over three tests is good for both creep and shrinkage tests and for all curing procedures. 


\section{ACKNOWLEDGEMENTS}

This research was supported by the Australian Cooperative Research Centre for Low Carbon Living. The experimental work was carried in the Structures Laboratory of the School of Civil and Environmental Engineering at the University of New South Wales. The assistance of the laboratory staff is also acknowledged.

\section{REFERENCES}

[1]. Wallah, S. E. \& Rangan, B. V., 2006. Low Calcium Fly Ash Based Geopolymer Concrete: Long Term Properties, Perth, Australia: Faculty of Engineering, Curtain University of Technology.

[2]. Wallah, S. E., 2010. Creep Behaviour of Fly Ash based Geopolymer Concrete. Civil Engineering Dimension, Vol12, No.2, September, pp. 73-78.

[3]. Sagoe-Crentsil, K., Taylor, A. \& Brown, T., 2013. Drying shrinkage and creep performance of geopolymer concrete. Journal of Sustainable Cement-Based Materials, 2(1), pp. 35-42.

[4]. AS3600, 2009. "Concrete structures", StandardsAustralia.

[5]. ASTM C157, 2009. Standard test method for length change of hardened hydraulic-cement mortar and concrete.

[6]. Ng, T.S., Foster, S.J., 2012, "Development of a mix design methodology for high-performance geopolymer mortars", Structural Concrete 14 (2) PP. 148 - 156.

[7]. AS1012.13, 1992. "Methods of testing concrete Determination of drying shrinkage of concrete for samples prepared in the field or in the laboratory", StandardsAustralia.

[8]. AS1012.16, 1996. "Methods of testing concrete Determination of creep of concrete cylinders in compression", Standards-Australia

\section{BIOGRAPHIES}

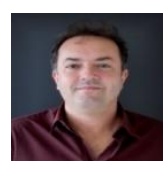

Arnaud Castel is Associate Professor in the School of Civil and Environmental Engineering at the University of New South Wales.

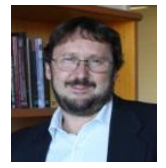

Professor Stephen Foster is Head of School, Civil and Environmental Engineering, University of New South Wales (UNSW).

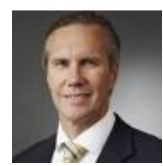

Dr. James Aldred is Technical Director at AECOM and Adjunct A/Professor in the School of Civil and Environmental Engineering at the University of New South

Wales. 